\title{
Pedagogies of Production: Re-imagining literacies for the digital age
}

Michelle Cannon and John Potter

\begin{abstract}
The authors reflect on the relationships between film, digital media and new literacy and learning practices. They explore the ways in which the study and production of audiovisual texts can be integrated into school settings, and the attendant new pedagogies to which film and media-making give rise. They consider the development of fluid and less hierarchical teaching practices that speak better to the everyday digital lives of children and young people in relation to the socio-political barriers to progressive education. Arguing in favour of more collaborative, social and dynamic literacies inclusive of the moving image, the authors support the view that film is one of the foremost art forms of the last and the current century.
\end{abstract}

The authors of this chapter would like to make suggestions as to how school experiences can be made more dynamic and more relevant to children and young people's digital lives outside school. We propose that one of the ways in which this might be achieved is through incorporating creative digital media and film production into the school day. By paying attention to existing theories on multiliteracies (Lankshear and Knobel 2011; New London Group 1996) and emerging thought on new pedagogies (Cannon 2018; Potter and McDougall 2017), we argue that a cultural and ideological shift in curriculum content and delivery will only come about after a reimagining of literacy in the digital age so as to include film and screen-based media (Bazalgette and Bearne 2010; BFI 2008; Potter 2012). In a bid to counter reform trends in the UK that constrain literacy practices and delimit the 
agency of teachers and learners, we seek to enliven debates around what counts as literacy through investigating creative practice around that most prominent of 21 st century art forms: film (FLAG 2015). The chapter is grounded in values supporting a plural and inclusive vision of literacy that is to do with offering routes to social participation relevant to learners' lives within their local context. Such a vision has wide-ranging implications for teaching and learning, as it moves objectives beyond achieving remote predetermined standards of reading and writing to embrace multimodal "signifying practices" (Hall 1997).

Digitization has clearly transformed screening and creative practices in the film industry, and these changes have been enacted on a global scale and with relative speed. The same cannot be said however for the comparatively glacial rate at which many formal education systems are embracing new technologies in relation to practical multimodal work. We suggest that this results from a number of social and cultural factors that might initially be addressed through enlightened and ambitious forms of pedagogy. For a rounded understanding of the issues, the chapter will be split into five parts that focus on the sociocultural context of our research studies, followed by the different sites of learning, and drawing on Lievrouw and Livingstone (2006), the devices/tools and the social arrangements/practices associated with new media in modern classrooms. We then conclude with some thoughts on pedagogies in the post-analogue age as well as ways forward for research and practice. Firstly, the authors contextualize this piece by outlining factors that constrain film and media practices in schools in England, such as the ideologically bounded parameters of literacy sanctioned by policy-makers, and the prevailing competitive and datadriven cultures in which schools are obliged to "perform" (Ball 2013). We explore emerging film education initiatives (Cannon et al. 2014; Potter and Bryer 2016), and draw on more established discourses related to media literacy (Buckingham 2003; Burn and Durran 2007) and popular culture (Marsh et al. 2005), that are seen to influence learner disposition and 
shape the formal and informal environments in which teaching and learning about film take place. Drawing on empirical data from projects with young learners aged $9-12$ involving poetry and iPad filmmaking, the authors argue in favor of teacher and pupil agency as a key element in production practices (Potter 2012). We investigate the hybrid "third" space of learning and digital display (Potter and McDougall 2017), the affordances of mobile media authoring tools and software, and the negotiated nature of pedagogies in moving image production environments. Teachers are envisioned as media literate practitioners capable of delivering multimodal and critically-framed school experiences as core literacy practices, and learners are conceived as co-producers of cultural filmic material (Cannon 2018).

\section{Contextual Constraints and Possibilities}

Film education initiatives in the UK have a long history going back to the 1980s (Bazalgette 1989), but there are still no formally recognized film and media components in the National Curriculum for the under 14s in England (other UK nations design different curriculum content, some of which include film and media literacy). The positioning of Film and Media Studies for older students is equally precarious as a result of the relatively low academic status accorded those subjects in public discourse (Buckingham 2014). Whether pupils in primary and early secondary schools learn about media or film at all is often down to teacher enthusiasts and local pockets of good practice in individual schools. This problematic PR, coupled with wider narratives of austerity, cuts to funding in arts and humanities programming, retrogressive reforms suspicious of digital media texts, and the punitive accountability measures demanded of schools combine to form something of a hostile climate for teachers who wish to engage with film and digital media-making in any form.

In our experience as educators and researchers, we believe that some primary-aged children, as young as 5 or 6 years old and across social demographics, bring digital skills and 
discrete cultural repertoires to the classroom for which there is no outlet or space in formal school structures. This enriching knowledge "capital”, although by no means universal, relates to many children and young people having been immersed in the consumption of popular cultural texts and the use of digital tools since they were toddlers. As numerous scholars have pointed out (Bazalgette 2010, Parry 2013), these particular funds of knowledge (Moll et al. 1992) are squandered in the early years, as learners enter into institutional regimes of literacy that exclude digital media texts and understanding of film. There may be a cultural explanation for this which revolves around issues of epistemology and power: we believe that literacy is an ideological rather than an autonomous phenomenon (Street 2003). By this we mean that being literate does not simply rely on a series of decoding skills - the acquisition of which is thought to automatically empower individuals with agency and improved life chances - rather, we argue that literacy is a condition that embodies a set of values and is sensitive to variable cultural contexts.

We relate film production to this more dynamic model of literacy in which the cultural capital of learners and their long-accumulating knowledge of the moving image, through TV, films, gaming and online interactions, is valued and made manifest. Building on what learners already know is an established pedagogic practice, and leveraging implicit film knowledge into the realms of production provides opportunities for familiar, pleasurable, and inclusive learning experiences. We argue that such practices can transform some of the more established print literacy activities, such as individual written tasks and reading comprehension, into collective, vibrant literacy events, in the sense that Brian Street (2003) described them, as socially situated occasions in which meanings are made and comprehended in new literacy practices (see also Potter 2012). We suggest that in educational spaces media events such as movie making, screening and discussing, are social happenings that have the power to interrupt established hierarchies and relationships within mainstream 
pedagogy in ways which may foster productive agency on the part of the learner. We believe that this is desirable because it contributes to the shift in the very definition of what literacy is, or could become.

\section{Sites: Dynamic Literacies and the Third Space}

In exploring the pedagogy of media production, two concepts are particularly important to us: “dynamic literacies" and "the third space" (Bhabha 1994; Gutierrez 2008; Potter \& McDougall 2017).

"Dynamic literacies" refers to the dynamic relationship between meaning-making practices and the wider culture. We have already set out our central belief that literacy, as an umbrella term, constitutes a wider set of practices than are traditionally represented in school curricula. These practices include the making and sharing of meanings across a range of textual forms in many modes, from video-blogging to musicmaking, animation to microblogging and photosharing, and more. Thinking of these practices as dynamic in the wider culture helps to distinguish them from those practices which are validated in static and performative aspects of the curriculum. Literacy is dynamic in the production of texts, the nature of the social arrangements around those texts, and the changing nature of the ways in which humans make and share meaning. It is undeniable that the visual forms of media are the predominant mode of communication in the $21^{\text {st }}$ century. At the same time, the circulation of print media is as prevalent on screen as non-print media, and humans are possibly reading more than ever, albeit in different forms and with different rule systems and syntax. The argument is really around the enlarging of the vision for literacy and not the demotion of teaching about print practices. Seeing the visual and the printed textual forms as co-existing in a dynamic relationship, accessed on the screen together, in moving image and still image 
texts in the curriculum would mirror their relationship in the world, that is, in the daily media culture in which children and adults pass their lives outside of school.

How a society defines literacy determines how it defines all teaching and learning, because having accepted that literacy is ideological and contested, we see how such relations currently determine schools as spaces in which performative measures and targets determine practices. In this way, literacy is in a push and pull relationship with pedagogy (Potter and McDougall, 2017) If we think of literacy as dynamic, then our teaching and learning will also be dynamic and inclusive, and we will be more ambitious with our curricula for our students.

The "third space" offers us a way forward as a place in which to explore these changing forms of curriculum experience as well as a way of conceiving them. The "third space" is a metaphorical location for teaching and learning in which hierarchies are dissolved and the cultural experiences of children and parents are welcomed as location for different forms of educational experience. This might be in an after-school club in which the demands of assessment are relaxed and do not dominate the experience of teaching and learning. Equally, they could be in a museum, a library or other location which is neither school nor home. It has also been argued elsewhere that such a space can come into existence in settings in which the agency of learners is valued and given space to create what Bhabha (1994) refers to as a "pact of interpretation" a recognition that the true location of meaning making in a culture is negotiated and contingent.

So far, this discussion of sites is abstract and theoretical. Locating the discussion in a real experience, in a real place, may be helpful in getting the point across further. In making movies with tablet devices in a project in East London with children who were of both primary and secondary school age, researchers noted several ways in which the experience in the "third space" of an after school club demonstrated potential for opening up spaces within the curriculum for even closer engagement with both popular culture and moving image 
language (Potter \& Bryer 2016). Two highly successful short films were written, shot and produced during a series of weekly summer term workshops. The children, younger and older, engaged in playful and dynamic forms of media composition, drawing on explorations of short clips from famous films. They shot and acted together every week with focus and attention to details, building up the productions by constantly reviewing what they had and how to move on.

In other words, in this "third space", freed from the standard curriculum constraints, the children were able to explore, over a greater period of time, the iterative and dynamic experience of filming and reviewing, making short clips, viewing them, making rough edits and returning to take more shots, all on the same device in which the practices of filmmaking are now converged. More importantly perhaps, the roles in the "third space" of instructorexpert and student were changed and allowed to blur somewhat. As the authors noted afterwards:

We identified a key factor in the success of this project as a willingness on the part of the filmmaker / facilitators to employ a flexible pedagogy which negotiated the demands of learning the craft skills and grammar of the moving image alongside the exploration of tablet devices... Facilitative roles may shift and change over time, but these artifacts are co-present with human actors in wider culture and require sensitive pedagogical intervention which is cognisant of their potential for all learners to engage productively with new and wider definitions of what it means to be literate. (Potter \& Bryer 2016: 124-125)

Of major importance in this activity was the way in which the potential for action on the world, the "affordance" of the tablet devices, enabled a haptic and dynamic engagement with 
the production of short films. In the following section we develop this notion further in a similar but longer-term project.

\section{The Affordances of Digital Media Tools}

Readers will appreciate that our call for bolder approaches to teaching and learning about and within the modern textual landscape must include the ability to access, critique, and make media texts, and at the very least, short form video clips in a variety of genres using a range of communicative tools and software. In the formal curriculum, this kind of activity is often aligned with English, by virtue of its association with the interrogation of texts. This section then offers pedagogic perspectives on a research study involving the use of iMovie on iPads in a Year 7 "subject" English setting (ages 11-12 years old). The convergent creative functionality of the iPad and other tablet devices enables learners to make and act on critical choices in the moment of production. We use the word "affordances" to describe the relationship between the users' intentions, what digital tools allow and the pedagogic climate in which learners are immersed.

Our premise for the merits of film production as a new literacy practice rests on the opportunity for overt authorial choice that digital tools enable in the appropriate teaching environment. In this account, pupils' creative media encounters are framed around three affordances of digital imaging tools that facilitate:

- experimentation \& improvisation

- reviewing and redrafting

- learning autonomy

(Burn and Durran 2007) 
We believe these to be important dimensions of the filmmaking process that foster agency in young learners and ultimately a sense of control over a medium with which many will have been familiar since birth. A study was conducted in a South London secondary school with Year 7 pupils during a series of English lessons in which film-watching and filmmaking were employed as a means of grounding their capacity to think critically. The English teacher, Chris Waugh, brought practices over from his native New Zealand, where digital media and film are already embedded into the core curricula (New Zealand Curriculum 2018). The pupils had watched a short film called Two Cars One Night (2004), a short, well-crafted black and white movie featuring an encounter between two young people in a car park. They examined the text for meaning and mood, as one might in the process of traditional literary criticism. Meaning in film is rendered through a series of artistic shooting choices related to camera angle, distance, movement, and perspective, as well as through decisions made in the editing process on color, sound, shot juxtapositions, and pace.

After a carefully managed plenary discussion about which of these elements the pupils had noticed in the film, they imagined how they might reshoot the film, and then drew by hand some alternative shots at different moments of the narrative. Such an approach removes any sense of inevitability about media representations and reframes them as tangible layered human constructs, and as outcomes of a series of negotiated, aesthetic, cognitive, and rhetorical choices on the part of the maker. Our experience suggests that allowing children to participate in processes of planning, shooting, editing, and display is an empowering literacy practice that can have lasting positive effects on learner identity.

The next stage in the process was to have the pupils practice their reimagined shots with iPads in the playground. Improvising with purpose and freedom of movement, they were encouraged to experiment with framing, composition, and distance so as to practice their art 
and maximize feelings of control and confidence. Most pupils independently progressed to using the iMovie app to edit their shots: the intuitive nature of the software meant that collaborative reviewing and redrafting followed in rapid succession, with continual judgements being made about the relative strengths of clips, sequences, and sounds. "Failing" fast and often is a welcome constituent of filmmaking activity, as is the open-endedness of the artefact which can be endlessly improved and reworked. For learners less confident with written inscriptions, the "mistakes" we make when shooting and editing become simply part of the process - the stakes are lower when the rightness or wrongness of linguistic performance is based on appeals to evocativeness rather than standards of accuracy. As in most arts practice, paying pedagogic attention to relations between form, content, and audience interpretation develops what Eisner has described as "judgment in the absence of rule" (2005). We maintain that this elusive skill is what is being lost in the rush to embrace the testing of academic knowledge and rote learning as an education system's gold standard. Just as might be expected of learners in the context of written responses to literary texts, the cognitive and critical awareness that accrues whilst making short films is arguably of comparable relevance and importance (Burn and Durran 2006; 2007). More on the cognitive dimension of filmmaking can be read in Mark Reid's chapter in this volume where he describes the ways in which a French film education program tackles the intrinsic and extrinsic virtues of the medium.

When the newly convergent multimodal features of tablet devices unite with creative constraints around a practical media task, a climate is produced which is conducive to autonomous learning. In an interview conducted during doctoral investigation, Chris Waugh offers a rationale for moving fluidly through multiple modes in his English teaching with ubiquitous use of digital devices: 
The whole interview is available at: https://soundcloud.com/shelleuk/phd-interview-

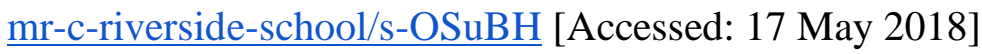

(at $0.31^{\prime}$ )

... viewing and making is actually a very parallel process to reading and writing, so you teach them in a literature class ... you can teach them in the same ways, and you can use the benefits of one in the domain of the other ...

(at 02:52')

... they're going to ultimately create a film that demonstrates an appreciation for those skills and techniques, and they'll also write about the original film, where they reflect on how the film-maker did this. So it's not radical at all, it's completely within the domain - it's entirely within the domain of English learning in secondary school, the work they're doing. You know, it's not a deviation or a holiday from it.

(at 39:38')

So instead of me showing them a film and then telling them how to respond to it critically, and what valid critical responses would be, and then asking them to reproduce what I've said in their own writing, as a film criticism, or a film review, they are being asked instead to look at aspects of the film that they find interesting or that they have thought to be successful, and to reproduce those in their own process of filmmaking. So that they can explore what the director's role is in making a film, so that then when they are ultimately asked to respond to the film, and the director's decisions within the film, they'll do it from a place of knowing as opposed to a place of being told. So they will be able to, I hope, come up with both more sophisticated and also more authentic responses to the original text, and they'll be able to talk with a sort of sophistication that I need them to, but about the things that they see rather than the things that I tell them are there ... this is the exploration, learning phase. 
(Cannon 2018. Interview with English teacher Chris Waugh)

Any reader wishing to listen to Waugh's interview in its entirety will note the extent to which he laments the low status of the moving image in the English education system and the ingrained hierarchical nature of pedagogy. In his teaching practice, he fully exploits digital media platforms and mobile tools in recognition that they are the main means through which young people organize and make sense of their lifeworlds outside school. In addition, mobile digital devices ease the way for pupils to be owners of their own learning habits and routines, responsibilities that he entrusts to his students, thereby unsettling habitual power relations in the classroom. Waugh expresses how being literate is and always has been a transmedia social and cultural exchange; accordingly, he employs the most appropriate means to cultivate critical thinking, creative production and cultural awareness (Burn and Durran 2007). In the context of creative writing, this is done not at the expense of analogue activities but in conjunction with them, using hand-drawn storyboarding techniques, the compositional potency of film and the multi-functionality of new media technologies.

\section{Film as a Present Social Practice}

Much of the pedagogic theory in this chapter is influenced by the rich findings of the Signature Pedagogies report (Thomson et al. 2012) which explains the modus operandi of a range of creative practitioners working in schools during the Creative Partnerships (CP) program that took place in the UK from 2002 until 2011 (Parker 2013). Listed below are some of the pedagogic dimensions common to many of the creative learning settings explored in this $\mathrm{CP}$ research. They seem to sit in stark contrast with the often reductive routines of accountable schooled literacies: 
- inclusion

- choice and agency

- scale and ambition

- the carnivalesque - in the playful sense of norms being overturned (Bakhtin 1981)

- the lived experience of the present

(Thomson et al. 2012)

We see correlations between these components of creative practice and those that relate to teaching and learning with film. It is, however, the final element connected to presence and the lived moment, that we consider to be worthy of more scrutiny in this chapter. The work of creative practitioners is rarely linked with curricula achievement, thus they are afforded the luxury of facilitating playful and essentially present, and often highly social making activities. Importantly, with only a blurred and ill-defined sense of what any end product might look like, learners grasp the possibility of having a stake in the process, unlike outcomes modelled a priori. These are the conditions in which thought, feeling, and emotion are brought into alignment, a state in which learners actively negotiate a "practical consciousness of a present kind, in a living and interrelating continuity" (Thomson et al. 2012: 32, drawing on the work of Raymond Williams 1977). Our contention is that media production practices, such as filming, animating, and editing can help to ground pupils' conceptual, perceptual and representational meaning-making capacities in present and material ways. Under specific mentored conditions, interstitial or liminal spaces (Burn and Durran 2007) are opened up for constructive dialogue and exchange between pupils, which we propose concretizes the conceptual work of literacy. 
It is difficult to separate practices from the tools and sites of learning in a digital environment, so intertwined is the network of virtual and physical relations in which they are embedded. Our approach to examining these practices is to extrapolate the human side of film production in schools, and it is with this in mind that we turn our attention to the social and affective dimensions of filmmaking. It is axiomatic that filmmaking requires teamwork and the taking up of roles: both teamwork and role-taking are familiar aspects of game play and sports activities, thus they are already in the purview of many children and young people. Once roles are defined, allocated and practiced by making risk-free brief clips (see Chapter 5 of Cannon 2018), the social contours and rhythms of creative media work are established. In order to demonstrate some of these features, the authors outline two case studies in formal and informal research settings where child-focused media-making was central. The first concerns a primary after-school filmmaking club - The Clip Club - which was set up in a diverse, low income area of East London over a period of 18 months. The second reports on a series of workshops in which children aged 5 to 11 learned to interpret and illustrate poetry through animation. It is hoped that providing empirical examples of situations in which teachers and children are co-agents in creative arts practice, will illustrate the benefits of developing social and collaborative media projects as a legitimate literacy practice.

The Clip Club, conceived and coordinated by one of the authors of this chapter (a full exegesis of Michelle's club and its filming activities can be found in Chapter 4 of Cannon 2018), comprised a group of seven children aged 9 to 10 years. All of the club's meetings were documented on a blog designed with the children in mind in order to record and celebrate their work in a lasting way (see: http://theclipclub.co.uk). Club members experienced a variety of different digital making activities over the months, culminating in the planning, shooting, and editing of two short films. The blog documents many occasions during which the children were highly engaged and working productively and independently, 
but rather than reproducing these activities here (all of which can be accessed online), we wish to give voice to one of the young participants who made a passionate address to camera inviting others to the club. We feel that this video clip demonstrates the importance of channeling child learners' energies towards a collective creative endeavor, one that speaks their language - the language of the moving image.

Dual 2 (his self-chosen pseudonym) had been asked to film himself talking about his experiences in the club: see Clip 4 from 02:00 - 04:00 mins https://vimeo.com/142087018 (password: wizard), where we see Dual 2 filming inside the geography cupboard. It is the intensity with which his words are spoken that makes for an arresting testimony supporting flatter negotiated pedagogic relations. There are two main thrusts to his hypothetical case for joining the Club: firstly, in a departure from the norm, "you don't get told off," and secondly, it is a place of security and support. In his own words, it represents a surrogate and provisional "family." Dual 2's mode of address at these two junctures re-affirms the intensity of what appear to be deeply felt emotions. There is a point at which he pauses and scratches his head, as if his usual school identity had been short-circuited by some pleasing turn of events, in other words, the mobilization and valuing of his existing media-related knowledge. Further, where he likens the Club to being in an "inspirative" team, a family, this could be interpreted as Dual 2 enjoying the security and stimulation of an alternative habitus (Burn 2009) - a "not-home-not-school" community of learning (Sefton-Green 2013). Burn recoups habitus to describe the school territory in which media texts - especially those drawn from popular aesthetics - meet educational experience. This is a zone where institutional procedures:

meet, merge, collide with subjective, embodied experience, aspiration, desire ... In Bourdieu's scheme [habitus] is the system of dispositions in which 
objective structures meet subjective thoughts, actions and perceptions.

(Burn 2009, p.11)

Up to this point, Dual 2's thoughts, actions and perceptions had been stewarded in inclusive ways, offering agency and challenge. Rather like the creative choices made in the processes of editing, film and media production pedagogy is about knowing how and when to adjust or preserve the raw conditions of the present; in short, to be alert to the collision of which Burn speaks above. This is what constitutes Dual 2's deeply personal "inspirative" moments, which for him have been largely elusive in the formal school day.

Filmmaking is a challenging creative practice that treads a fine line between structured discipline and autonomous agency, between the planned and the improvised. When facilitated with attention to these dichotomous elements, pupils like Dual 2 are attracted to the freedoms on offer within the safe constraints of a recognizable and familiar art form. The self-direction and intrinsic motivation that many teachers seek to develop in their students are witnessed in Dual 2's clip, and the one to follow that sees him co-editing with his classmate, Nimbus. See Clip 5 from 04:00 - 06:30 mins https://vimeo.com/142087018 (password: wizard), where two friends with different approaches to editing (and different attitudes to school work in general) engage in social, collaborative, and self-directed learning at the interface. The principles of the creative process outlined above in tandem with the aforementioned features of digital tools, are made manifest in this clip. Cannon adds further interpretive layers exploring the craft dimensions of film production where the boys conduct themselves as apprentices:

I describe the artistry of DV editing as rhetorical performance in that the boys are engaged in a task that actively combines aesthetic sensibilities with pragmatic intention, 
and which expresses the sophisticated and often contradictory thinking that editing can bring about. There is no right or wrong way to proceed but the boys' distinct approaches signal a difference in character and mode of operation: the one cautious and systematic with an eye on future action, the other impulsive and focussed on results in the now. Despite these differences, they manage to share the keyboard and listen to each other's ideas, sometimes the one instructing the other, negotiating the software as they go. Audiovisual curation at the interface - selecting, re-ordering, and re-assembling digital assets - is thus rendered a dialogic and tangible craft that caters to both the mercurial and the constant. These are the kinds of skills and dispositions that literate multimodal composers might develop alongside writing, for creative, narrative or explanatory expression across the curriculum.

(Cannon 2018, p.150)

By taking on the role of inexpert video editors then, the children experience firsthand the ebb and flow of a literacy event mediated in the present by new technologies and social interaction.

So far, this section has described the nature of filmmaking located in informal, liminal spaces, where the pedagogy associated with multimodal meaning-making resides largely in the preparatory groundwork, and in the extent to which teachers are then able to enact "skilful neglect" (Loveless 2008). In other words, pupils are left immersed in their making world, enabling them to experience the challenges, explore the possibilities, and draw collectively on implicit moving image skills and repertoires. Similar practices can be employed in the formal curriculum in relation to the ways in which stop motion animation can enrich young learners' engagements with poetry. 


\section{Media Production and the Formal Curriculum}

Earlier in the chapter we stated that the aim of our work was not to supplant the traditional literacy curriculum but to enlarge it and be more ambitious about how we work across forms of meaning-making. Stop-frame animation was used in a project called "Persistence of Vision," located in the formal curriculum in the teaching of non-narrative poetry (Bazalgette, Parry, \& Potter 2011). It was posited that the teaching of non-narrative poetry could be enhanced by learning about stop-frame animation, and that the teaching of animation could be enhanced by learning about non-narrative poetry; a focus on image and rhythm, timing and visual metaphor being something which both forms have in common. The aim of this project, therefore, was to discover the ways in which the two forms could work symbiotically to develop important concepts in both domains.

Pedagogically speaking, the project carried a number of potential risks: firstly, the interference in the daily running of literacy learning in the school day (this was not an afterschool club intervention), and secondly, the introduction of technology and media into a complex ecosystem of child and teacher skillsets, time constraints, and so on. Early on, the decision was taken to work toward embedding the experience in the real world of the classroom. By this we mean that the intervention was not a project which was to be helicoptered into the space, run by an external expert, and then left to bear no significant influence on learning over time. The decision was taken to enable the teachers to practice the techniques in significant amounts of staff development time, to take the equipment with them back to school, and to use it over a period of months whenever they were teaching about poetry and animation. Meetings were held regularly through the school year to identify what worked and what did not work. 
Children composed short, animated sequences after listening to poems or studying one or two lines of images. They also worked the other way round, reverse-engineering poems, in other words starting from their own animations and working back into print forms, from their own short, animated sequences, some of which were stimulated by sounds (wind, rain, even an old-fashioned dial-up modem connecting). Over time, through the iterative development of a series of activities, some significant gains were made by students in each of the three geographically-separated, rural locations.

Teachers reported that 'Persistence of Vision' was successful in enhancing acquisition of writing skills, particularly with respect to enriching language use in various non-narrative contexts. Here it is clear that the project was successful in connecting the media form to the formal requirements of the curriculum, and this success bears out the role posited by a number of academics for media work alongside text (see for example Bearne 2009: 156-187).

In an example of working from poetry to animation, children in one school took the formal structure of a piece called 'What is the sun?' by Wes Magee (2001) in which the author provides a series of metaphors for the sun, and produced a class poem called "What is the moon?" Line by line they animated their metaphors in groups (sample: it is a mint rolling down a hill...) using stop-frame techniques with flat bed or 3-d animation. Moving in the other direction, two very young children animated, using the sound system of an old modem dial-up sound, the famous hardware handshake. To them it sounded like alien spaceships talking to one another and they used simple cut paper shapes on a flat black background. They were then encouraged to turn their animation into words, by use of simile and metaphor and to generate poetry in this way.

All of the features of media production pedagogy we have discussed so far were present in the work, from a connection to media culture, through to the iterative nature of learning about the structure and grammar of moving image production. Moreover, media 
production was also inflected with traditional print literacy forms and the need to work with poetry of a non-narrative nature in an act of enlargement of literacy itself and an engagement with the modes and tools of meaning-making in digital culture.

\section{Pedagogic Recommendations}

In this chapter we have offered accounts of the successful implementations of film and media initiatives in both formal and informal school environments focusing on the sites, tools, and practices of "signature pedagogies" with digital media. The term originates from Shulman's (2005) influential study of teaching practice in professional environments. His insights have been applied in other domains including creative arts practice (Thomson et al. 2012), one of the key ideas being that the optimum conditions for learning vary according to context. This suggests that centralized efforts to prescribe particular modes of teaching are likely to be ineffective, given the peculiarities of each school's available resources, leadership, and sociocultural and geographic settings. We argue that the agency of teachers starts with the recognition and celebration of the uniqueness of their environment - an individuality that could be captured in both digital and analogue forms. In order to enact this, it is proposed that teachers could begin with enhanced teacher training and ongoing career professional development over a sustained period of time in relation to film and media production. This is not with a view to teachers becoming expert practitioners, but with a view to them becoming creatively and critically engaged with their own and their pupils' everyday media landscape.

Much inspiration can be drawn from progressive international curriculum approaches that include film education and make alliances with existing agencies. A fresh model from New Zealand has already been cited, and for the Finns, film and TV education in schools has a long history: Koulukino (School Cinema Association) and the Media Education Centre Metka 
promote film as part of media education, and the National Audiovisual Institute enhances film education and the status of Finnish audiovisual culture as part of its legal duties (KAVI 2013).

\section{Perplexity and Optimism}

As an exercise, if one were to do a Google image search on media literacy frameworks, one would be confronted with scores of colorful infographics from around the industrialized nations, many of which remain at the level of abstractions rather than as deployed and evaluated programs of learning, a state indicative of our continuous search for ways of negotiating and categorizing our entanglements with media on a global scale. As a subset of media education, film education frameworks are far less common, and largely derive from a small network of European agencies and organizations (see for example various EU-funded British Film Institute projects with European partners such as FLAG 2015). As a discrete art form with intrinsic cultural and educational value, this burgeoning field of film and media studies sees learning about and through film as a core entitlement in schools. A groundswell of international research projects and initiatives is emerging - including the new Film

Education Journal, whose first issue is imminent via the IoE Press - which promises to build capacity around this vast and neglected educational dimension of 20th and 21st century visual culture.

It has been suggested in this piece that there is a damaging poverty of aspiration in the English education system, reflected in the ways in which engagements with film and digital media are regarded with suspicion, sidelined, and consigned to the realm of consumption and entertainment. This may be due in part to the persistent alignment of film with popular culture which has no place in current curricula; however, in a historical moment in which the socially diverse nature of educational institutions is of increasing significance, the universal 
language of film could play an important role in building intercultural understanding and wider cultural repertoires across social and ethnic groups. For this and many other reasons, we urge school leaders to adopt a proactive approach to the moving image, in which teachers and children are given the opportunity as co-agents to drive the process of changing schools' relationship to film. Ultimately, we continue to wonder why it is that children in certain developed nations are not authorized to be as discriminating about what they see, hear, and make, as it is deemed they ought to be about what they read and write. Perhaps localized grass-roots pedagogic action is the way forward to shift the boundaries of legitimate meaning-making practices to account for the audiovisual and to cater for more diverse cultural affiliations.

\section{References}

Bakhtin, Mikhail. 1981. The Dialogic Imagination: Four Essays. Austin: University of Texas Press.

Ball, Stephen J. 2013. The Education Debate. 2nd ed. Bristol: Policy Press.

Bazalgette, Cary, Becky Parry \& John Potter. 2011. “Creative, Cultural and Critical: Media literacy theory in the primary school classroom." Paper presented at the Creative Engagements 7, Mansfield College, Oxford University., 4-7 7 $^{\text {th }}$ July, 2011

Bazalgette, Cary, and Eve Bearne. 2010. Beyond Words: Developing Children's Understanding of Multimodal Texts. Leicester: UKLA.

Bazalgette, Cary. 1989. Primary Media Education: A Curriculum Statement. London: British Film Institute.

Bazalgette, Cary. 2010. Teaching Media in Primary Schools. Edited by Cary Bazalgette. London: Sage. 
Bazalgette, Cary. 2018. "Some Secret Language: How Toddlers Learn to Understand Movies." PhD Thesis. UCL, Institute of Education, University of London.

Bearne, Eve. 2009. "Multimodality, literacy and texts: Developing a discourse." Journal of Early Childhood Literacy 9 (2): 156-187.

Bhabha, Homi. 1994. The Location of Culture. London: Routledge.

British Film Institute Education. 2008. "Reframing Literacy.” London: British Film Institute. Available at: http://www.bfi.org.uk/sites/bfi.org.uk/files/downloads/bfi-educationreframing-literacy-2013-04.pdf.

Buckingham, David. 2003. Media Education: Literacy, Learning and Contemporary Culture. Cambridge, UK: Polity.

Buckingham, David. 2014. "The Success and Failure of Media Education.” Media Education Research Journal 4 (2): 5-17. Available at: http://merj.info/wpcontent/uploads/2014/01/MERJ_4-2-Editorial.pdf.

Burn, Andrew. 2009. Making New Media: Creative Production and Digital Literacies. New York: Peter Lang.

Burn, Andrew, and James Durran. 2006. "Digital Anatomies: Analysis as Production in Media Education." In Digital Generations: Children, Young People, and the New Media, edited by David Buckingham and Rebekah Willett, 273-93. London: Routledge.

Burn, Andrew, and James Durran. 2007. Media Literacy in Schools: Practice, Production and Progression. London: Paul Chapman.

Cannon, Michelle, Theo Bryer, and Morlette Lindsey. 2014. "Media Production and Disruptive Innovation: Exploring the Interrelations between Children, Tablets, Teachers and Texts in Subject English Settings.” Media Education Research Journal 5 (1): 16-31. 
Cannon, Michelle. 2018. Digital Media in Education: Teaching, Learning and Literacy Practices with Young Learners. London: Palgrave Macmillan.

Eisner, Elliot. 2005. Reimagining Schools: The Selected Works of Elliot W. Eisner. Abingdon: Routledge.

FLAG (Film Literacy Advisory Group). 2015. “A Framework for Film Education.” London. Available at: http://www.bfi.org.uk/sites/bfi.org.uk/files/downloads/ bfi-a-frameworkfor-film-education-brochure-2015-06-12.pdf.

Gutierrez, Kris. 2008. "Developing a sociocultural literacy in the third space.” Reading Research Quarterly, 43 (2), 148-164.

Hall, Stuart. 1997. Representation: Cultural Representations and Signifying Practices. London: SAGE Publications.

KAVI (Finnish Media Education Authority, National Audiovisual Institute). 2013. "Finnish Media Education." Helsinki. Available at: https://kavi.fi/sites/default/files/documents/mil_in_finland.pdf.

Lankshear, Colin, and Michele Knobel. 2011. New Literacies: Everyday Practices and Social Learning. Maidenhead: Open University Press.

Lievrouw, Leah, and Sonia Livingstone. 2006. Handbook of New Media: Social Shaping and Social Consequences of ICTs. London: Sage Publications.

Loveless, Avril. 2008. “Creative Learning and New Technology? A Provocation Paper.” In Creative Learning, edited by Julian Sefton-Green, 61-71. London: Creative Partnerships, The Arts Council.

Magee, W. 2001. The Very Best of Wes Magee. London: MacMillan.

Marsh, Jackie, Greg Brooks, Jane Hughes, Louise Ritchie, Roberts Samuel, and Katy Wright. 2005. “Digital Beginnings: Young Children's Use of Popular Culture, Media and 
New Technologies." Sheffield: University of Sheffield. Available at:

https://issuu.com/esmeefairbairn/docs/digitalbeginnings-report

Moll, Luis C., Cathy Amanti, Deborah Neff, and Norma Gonzalez. 1992. "Funds of

Knowledge for Teaching: Using a Qualitative Approach to Connect Homes and Classrooms." Theory Into Practice 31 (2): 132-41.

New London Group. 1996. “A Pedagogy of Multiliteracies: Designing Social Futures.” Harvard Educational Review 66 (1): 60-92.

New Zealand Ministry of Education. 2018. "The New Zealand Curriculum.” Wellington, NZ. Available at: http://nzcurriculum.tki.org.nz/The-New-Zealand-

Curriculum\#collapsible10.

Parker, David. 2013. Creative Partnerships in Practice: Developing Creative Learners. A\&C Black, London.

Parry, Becky. 2013. Children, Film and Literacy. Basingstoke: Palgrave Macmillan.

Potter, John, and Julian McDougall. 2017. Digital Media, Culture and Education: Theorising Third Space Literacies. London: Palgrave Macmillan.

Potter, John, and Theo Bryer. 2016. “'Finger Flowment' and Moving Image Language:

Learning Filmmaking with Tablet Devices.” In Literacy, Media, Technology: Past, Present and Future, edited by Becky Parry, Cathy Burnett, and Guy Merchant, 11128. London: Bloomsbury.

Potter, John. 2012. Digital Media and Learner Identity: The New Curatorship. New York: Palgrave Macmillan.

Sefton-Green, Julian. 2013. "Learning at Not-School: A Review of Study, Theory, and Advocacy for Education in Non-Formal Settings." The John D. and Catherine T. MacArthur Foundation Reports on Digital Media and Learning. Cambridge, MA: 
Massachusetts Institute of Technology \& Monterey Institute for Technology and Education (MITE).

Shulman, Lee. S. 2005. "Signature Pedagogies of the Professions." Daedalus 134 (3): 52-57.

Street, Brian. 2003. "What's 'New' in New Literacy Studies? Critical Approaches to Literacy in Theory and Practice." Current Issues in Comparative Education 5 (2): 77-91.

Thomson, Pat, Christine Hall, Ken Jones, and Julian Sefton-Green. 2012. "The Signature Pedagogies Project: Final Report.” Newcastle-upon-Tyne. Available at: http://cprtrust.org.uk/wpcontent/uploads/2015/02/signature_pedagogies_report_final_version_11.3.12.pdf.

Two Cars, One Night. 2004. Dir. Waititi, Taika. Film. Defender Films Ltd. New Zealand. Williams, Raymond. 1977. Marxism and Literature. Oxford: Oxford University Press. 